\title{
Shh maintains dermal papilla identity and hair morphogenesis via a Noggin-Shh regulatory loop
}

\author{
Wei-Meng Woo, Hanson H. Zhen, and Anthony E. Oro ${ }^{1}$ \\ Program in Epithelial Biology, Stanford University School of Medicine, Stanford, California 94305
}

\begin{abstract}
During hair follicle morphogenesis, dermal papillae (DPs) function as mesenchymal signaling centers that crosstalk with overlying epithelium to regulate morphogenesis. While the DP regulates hair follicle formation, relatively little is known about the molecular basis of DP formation. The morphogen Sonic hedgehog (Shh) is known for regulating hair follicle epithelial growth, with excessive signaling resulting in basal cell carcinomas. Here, we investigate how dermal-specific Shh signaling contributes to DP formation and hair growth. Using a Crelox genetic model and RNAi in hair follicle reconstitution assays, we demonstrate that dermal Smoothened (Smo) loss of function results in the loss of the DP precursor, the dermal condensate, and a stage 2 hair follicle arrest phenotype reminiscent of $\mathrm{Shh}^{-/-}$skin. Surprisingly, dermal Smo does not regulate cell survival or epithelial proliferation. Rather, molecular screening and immunostaining studies reveal that dermal Shh signaling controls the expression of a subset of DP-specific signature genes. Using a hairpin/cDNA lentiviral system, we show that overexpression of the Shh-dependent gene Noggin, but not Sox 2 or Sox18, can partially rescue the dermal Smo knockdown hair follicle phenotype by increasing the expression of epithelial Shh. Our findings suggest that dermal Shh signaling regulates specific DP signatures to maintain DP maturation while maintaining a reciprocal ShhNoggin signaling loop to drive hair follicle morphogenesis.
\end{abstract}

[Keywords: Hedgehog pathway; dermal papilla; hair follicle; Noggin]

Supplemental material is available for this article.

Received January 13, 2012; revised version accepted April 25, 2012.

Epithelial organs, including hair follicles, teeth, and mammary glands, share common developmental and regenerative strategies. Each begins with a local thickening of the epithelium and condensation of the underlying dermal mesenchyme and uses a series of reciprocal epithelialmesenchymal signals to coordinately drive the development of the two compartments (Hardy 1992; Millar 2002; Fuchs and Horsley 2008). In mice, pelage hair follicle epithelial placodes proliferate and grow downward in contact with and in response to the condensed dermal mesenchyme, termed the dermal condensate (DC). The DC further matures and becomes encased by the elongating follicular epithelium in forming the dermal papilla (DP). As a tissue organizer, the mature DP provides the major environmental influence on the epithelial stem cells, providing key signals that regulate the timing and type of hair follicle formed throughout the life of the organism (Oliver and Jahoda 1988; Driskell et al. 2011). For the anagen growth phase initiation, the DP provides stimulating signals such

${ }^{1}$ Corresponding author.

E-mail Oro@stanford.edu.

Article is online at http://www.genesdev.org/cgi/doi/10.1101/gad.187401.112. as Fgf7/10 (Greco et al. 2009) and TGF $\beta$ (Oshimori and Fuchs 2012). Additional growth factors Wnt3a and BMP6 are sufficient to maintain the DP hair inductive function (Kishimoto et al. 2000; Rendl et al. 2008), and DP-specific $\beta$-catenin/Wnt signaling plays a role in sustaining anagen hair growth and new hair induction in the first postnatal hair cycle (Enshell-Seijffers et al. 2010a,b). Other factors such as DP-specific Notch-Wnt5a signaling facilitate hair follicle differentiation (Lee et al. 2007; Estrach et al. 2008; Hu et al. 2010).

While the epithelial contributions to hair follicle growth have been extensively studied, relatively little is known about how the DP develops and functions in early hair follicle morphogenesis and growth. Recent work suggests that reciprocal interactions between the Wnt/ $\beta$-catenin and ectodysplasin pathways specify the early DC before the appearance of the placode (Zhang et al. 2009). In addition, PDGF signaling induces formation of ectopic DP in adult dermis, suggesting that dermal proliferation plays a role in DP formation (Karlsson et al. 1999; Collins et al. 2011). However, thus far, the only DP-specific signaling molecule that shows a role in hair follicle morphogenesis is the BMP antagonist Noggin. In noggin ${ }^{-1-}$ mice, hair follicles arrest at 
stage 2 during embryonic hair morphogenesis (Botchkarev et al. 1999; Jamora et al. 2003). Noggin regulates the expression of a number of DC/DP-specific molecules via BMP4-dependent and -independent modes and regulates hair follicle epithelial induction through Lef1 (Botchkarev et al. 1999; Jamora et al. 2003). Ongoing or late determinants that shape and maintain DP maturation remain to be determined.

Sonic hedgehog $(\mathrm{Shh})$ is one of the crucial hair follicle inductive signals generated in the hair follicle placode (Millar 2002; Fuchs and Horsley 2008). Studies in $\mathrm{Shh}^{-/-}$ and $\mathrm{Gli2}^{-/-}$mice show that Shh signaling is dispensable for hair follicle initiation, but is required for hair follicle down-growth past stage 2 of hair follicle development (St-Jacques et al. 1998; Chiang et al. 1999; Mill et al. 2003). In Shh- or Gli2-null hair follicles, epithelial proliferation is decreased, while the bulk of epidermal and hair epithelial differentiation is not affected. Shh target gene induction occurs in both the epithelium and the underlying DC, suggesting that reception of Shh signaling occurs in both compartments. Epidermal-specific gainof-function studies of Shh or pathway mediators, Glil, Gli2, and Smoothened (Smo), demonstrate that the epithelial role of Shh signaling in the early hair follicle epithelium is to drive epithelial proliferation (Dahmane et al. 1997; Xie et al. 1998; Grachtchouk et al. 2000; Huntzicker et al. 2006).

In contrast, conflicting information exists for how dermal Shh signaling regulates hair follicle morphogenesis. In $\mathrm{Shh}^{-/-}$or $\mathrm{Gli2}^{-/-}$developmentally arrested hair follicles, the DC is present but does not mature into a DP (StJacques et al. 1998; Chiang et al. 1999; Jamora et al. 2003). Epidermal Gli2 activator expression rescues the $\mathrm{Gli2}^{-/-}$ hair follicle phenotype, arguing against a dermal Gli2 role in hair follicle morphogenesis (Mill et al. 2003). In contrast, epidermal Gli2 expression only marginally alleviates the $\mathrm{Shh}^{-/-}$-arrested hair follicle, suggesting a Gli2 activatorindependent requirement of Shh signaling.

Here we directly examine the role of Shh on the hair follicle dermal compartment using both genetic and RNA knockdown approaches to remove dermal Smo in mice and in a hair follicle reconstitution assay. We found that hair follicles arrest at stage 2 from disintegration of the mutant DC. Smo controls the expression of a subset of DC/ DP-specific molecules, including Sox2, Sox18, and Noggin. Noggin overexpression bypasses defects from reduced Smo activity by increasing Shh ligand expression in the epithelium. Thus, epithelial Shh acts to regulate DP maturation and maintain DP functions via Noggin to drive hair follicle morphogenesis.

\section{Results}

Dermal-specific knockout of Smo results in hair follicle development arrest

To determine whether epithelial Shh directly regulates the underlying dermis in hair follicle development, we generated dermal tissue-specific Smo knockouts using Prx1cre. Prxl-Cre activity is spotty in the dermal mesenchyme of the ventrum, the limb buds, the interlimb flank, and a small domain on top of the head as early as embryonic day 10.5 (E10.5), then becomes uniform and strong ventrally at E16.5 (Logan et al. 2002). Within the hair follicle, Prxl-Cre activity was specifically expressed in the DP as well as the interfollicular dermis, but not the epithelial cells (Supplemental Fig. S1; Lehman et al. 2009). We verified the removal of Smo function in Prx1-cre; Smo ${ }^{f 1 / n}$ ( $f 1$ refers to the flox allele, and $n$ refers to the null allele) animals by assaying Smo and Shh target gene expression in E17.5 ventral dermis using quantitative PCR. Both dermal Smo RNA and Shh signaling target genes Glil and Ptcl were greatly reduced in Prx1-cre; Smo ${ }^{f l / n}$ ventral dermis (Fig. 1J), while their expression in the dorsal dermis was similar in control and Prx1-cre; Smo ${ }^{f 1 / n}$ embryos (data not shown).

The Prx1-cre; Smo ${ }^{f 1 / n}$ mutant animals were easily recognized due to a slightly smaller body and rudimentary limbs, consistent with a strong mesenchymal Shh signaling defect (Fig. 1A,C). At postnatal day 12 (P12), the ventral skin of Prx1-cre; Smo ${ }^{f l / n}$ mice displayed sparse hair growth pattern, particularly toward the anterior and posterior regions (Fig. 1C), while wild-type littermate controls displayed abundant hair growth (Fig. 1B). Prx1-cre; Smo ${ }^{f l / n}$ mice also displayed a bald region on top of the head and the lateral body in sites of Cre recombinase expression (Fig. 1A, arrows; Logan et al. 2002).

Next, we examined the hair growth defect by conducting histological analysis on Prx1-cre; Smo ${ }^{f l / n}$ hair follicle development at various time points. We found that hair follicle morphogenesis was normal in Prx1-cre; Smo ${ }^{f 1 / n}$ ventral skin at E16.5 and E17.5 (Fig. 1D,E; data not shown). However, hair follicle numbers were reduced in the mutants compared with control as early as E17.5 and also at P0 (Fig. 1D,E [arrows], N). Ventral skin at both P0 and P3 demonstrated severely retarded hair follicle morphogenesis (Fig. 1F-I). In P0 mutant skin, we observed arrested stage 2-3 hair germs without a recognizable DC, while in P3 mutant skin, we found that DC-free hair germs were capable of progressing to a stage 3-like morphology.

We confirmed the key role for dermal Smo by examining the expression of a Shh signaling reporter, Ptc1-lacZ (Goodrich et al. 1997). In Prx1-cre; Smo $o^{f l / n}$ skin, we detected Ptc1-lacZ-negative DCs, in contrast to lacZ-positive DCs in control (Fig. 1K,L). Quantification of hair follicles with Ptc1lacZ-negative DCs in Prx1-cre; Smo ${ }^{f l / n}$ reveals that $81 \%$ of dermal Smo knockout hair follicles were arrested at stage 2 and differed significantly from those in littermate controls $(P<0.05)$ (Fig. 1M). These data demonstrate that dermal Shh signaling is required for hair follicle progression past stage 2 . Together, Prx1-cre; Smo ${ }^{f l / n}$ hair follicle development defects are reminiscent of those seen in Shh-null skin.

\section{Loss of DCs in dermal Smo knockout skin}

In Prx1-cre; Smo ${ }^{f 1 / n}$ skin, the expression of keratin14, keratin17, P-cadherin, and laminin 511 were normal along the epidermis and early hair follicles (Fig. 2A-D; Supplemental Fig. S2), suggesting that early hair follicle epithelium undergoes normal differentiation and generates a normal 

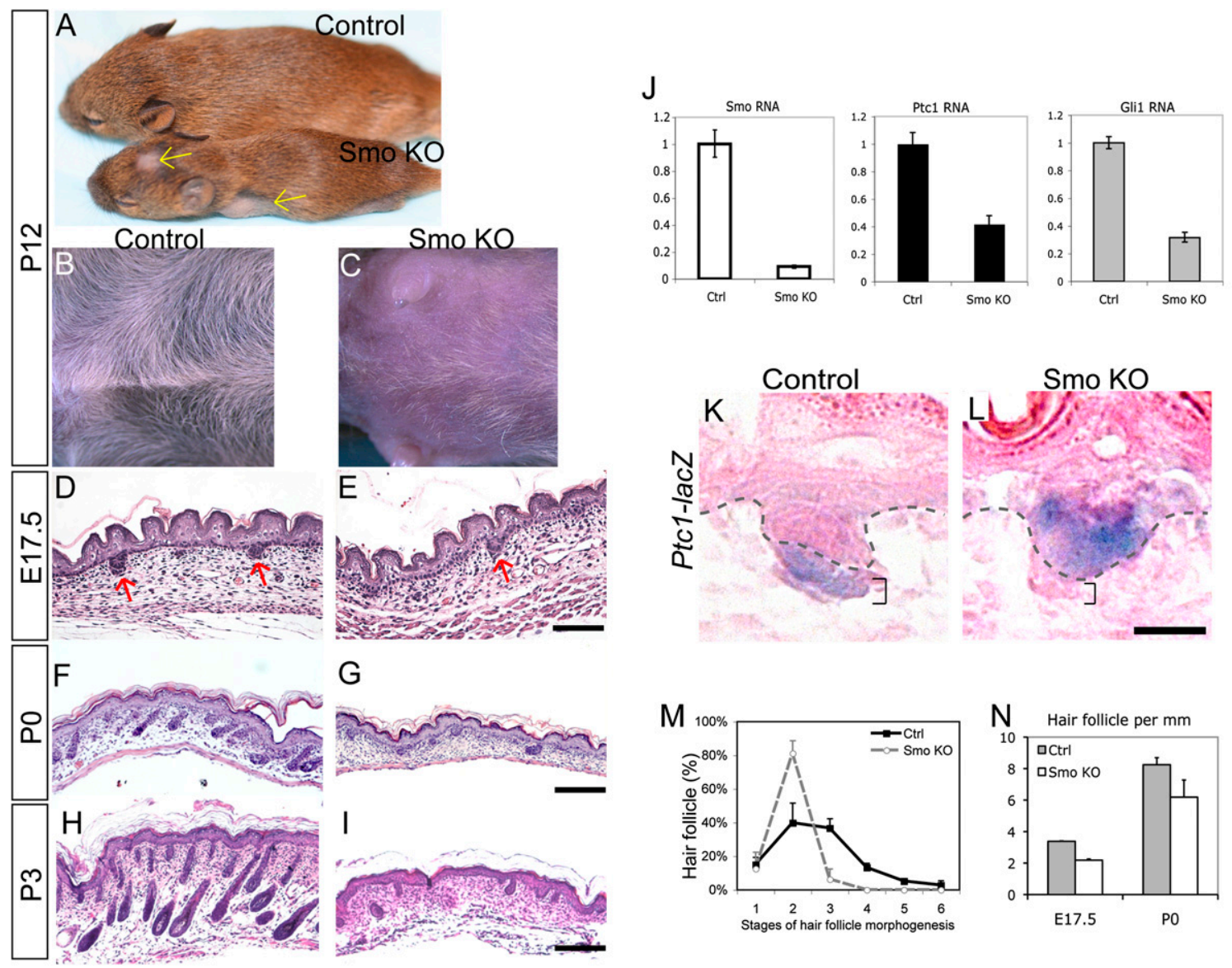

Figure 1. Smo knockout in ventral dermis impairs hair follicle morphogenesis. (A) Dorsal view of wild-type littermate (Control) and Prx1-cre; Smo ${ }^{f l n}$ (Smo KO) at P12. Hair growth on the dorsal skin of Smo knockout (Smo KO) was grossly normal. Note bald spots in the head and lateral area, where Prxl-Cre is also active (arrows). $(B, C)$ Ventral views of P12 mice. $(B)$ Dense ventral pelage hair in littermate control. $(C)$ Reduced ventral pelage hair in Prx1-cre; Smo ${ }^{f 1 / n}$. $(D-I)$ Hematoxylin and eosin-stained sections of littermate control and Prx1-cre; Smo ${ }^{f 1 / n}$ skin at E17.5 $(D, E), \mathrm{P0}(F, G)$, and P3 $(H, I)$. Arrows in $D$ and $E$ point to stage 2 hair germs. (J) Quantitative PCR of Smo, Ptch1, and Glil from E17.5 ventral dermis of control and Prx1-cre; $S_{m o}{ }^{f 1 / n}(N=2$ per group). $(K, L)$ Shh signaling induction in control and Prx1-cre; Smo ${ }^{f l / n}$ hair follicles as shown with Ptc1-lacZ reporter at E18.5. X-gal-positive signal is in blue, and sections were counterstained with eosin. Hair germs are outlined. Positions of DCs are indicated with single brackets. $(M)$ Analyses of hair follicle development stages of control and Prx1-cre; Smo ${ }^{f 1 / n}$. For Prx1-cre; Smo ${ }^{f 1 / n}$, only hair follicles with X-gal-negative DCs were counted as dermal Smo knockout (Smo KO). The differences from stage 2 to stage 5 are statistically significant $(P<0.05)$. $(N)$ Hair follicle density in control and Prx1-cre; Smo ${ }^{f l / n} . P<0.005$ and $P<0.05$ for E17.5 and P0, respectively. (Ctrl) Littermate control; (Smo KO) Prx1-cre; Smo ${ }^{f l / n}$. Error bars indicate SEM. Bars: $D, E, 100 \mu \mathrm{m} ; F-I, 200 \mu \mathrm{m} ; K, L, 20 \mu \mathrm{m}$.

basement membrane. However, notably absent were DC cells in stage 2 hair germs at P0 (Fig. 2D). The lack of DCs could be due to defects in initial recruitment or specification of the DC cells or failure to sustain the persistence or maturation process of the DCs. Consequently, we examined the DCs in Prx1-cre; Smo ${ }^{f 1 / n}$ ventral skin at E17.5 when Shh target gene expression was reduced (Fig. 1J). In both control and mutant animals, the DCs in the early follicles uniformly appeared normal (Fig. 2A,B). We detected a mild reduction in DC cell number in the mutants at late E17.5, suggesting that the DC was formed normally but was progressively lost from E17.5 to P0.

To confirm this observation, we examined the expression of the cell surface molecule CD133 and the enzyme alkaline phosphatase $(\mathrm{AP})$, early markers that define the
DC/DP (Handjiski et al. 1994; Ito et al. 2007). As shown in Figure 2, expression of both markers in Prx1-cre; $\mathrm{Smo}^{f 1 / n}$ at E17.5 was comparable with control follicles (Fig. 2E,F,IJ). However, in P0 hair follicles, the diminishing DCs of Prx1cre; $S m o^{f l / n}$ animals were apparent, with weaker or absent CD133 and AP expression (Fig. 2G,H,K,L).

To validate the Smo requirement for DC maintenance but not formation, we examined whether Smo protein expression was depleted in the E17.5 DC by immunostaining. We confirmed that Smo signal was lost in E17.5 Prx1-cre; Smo ${ }^{f l / n}$ DCs (Fig. 2O,P) but normal in the epithelium (Fig. 2O,P, arrow). In contrast, in the control sibling, Smo signal was evident in both the DC and the epithelium (Fig. 2M,N). Thus, dermal Smo is dispensable for the initial recruitment or specification of DCs. Together, we conclude 


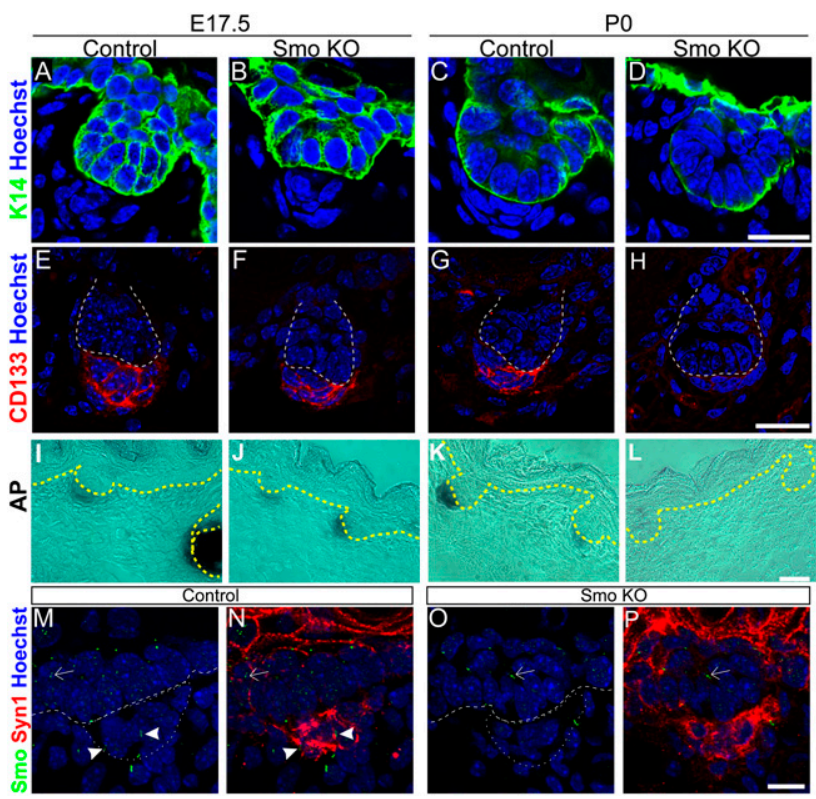

Figure 2. Prx1-cre; $S m o^{f 1 / n}$ hair germs display loss of DC cells. $(A-D)$ Stage 2 hair germs labeled with keratin 14 (K14) for epithelium and with Hoechst for nuclei. One representative hair germ is shown per panel. DCs were evident beneath the hair germ epithelium in $A-C$ but were undetectable in $D$. $(E-H)$ CD133 staining of DCs. In the diminishing smaller DC in Smo knockout (Smo KO) at P0, CD133 is either absent or very weak. $(I-L)$ AP staining (black) of the DCs. (L) AP activity was undetectable in the diminishing DCs at PO. $(M-P)$ Smoothened expression was undetected in Prx1-cre; $\mathrm{Smo}^{\mathrm{fl} / \mathrm{n}}$ DCs (dotted closed circle) at E17.5. Arrows and arrowheads indicate Smo signal in the epithelium and DCs, respectively. Bars: $A-H, 20$ $\mu \mathrm{m} ; I-L, 30 \mu \mathrm{m} ; M-P, 10 \mu \mathrm{m}$.

that dermal Shh signaling is required to maintain DCs at stage 2 of hair follicle growth, sustaining DC maturation.

\section{Smo knockout in the dermis does not affect cell survival or proliferation}

To determine whether the maintenance of the DC requires ongoing Smo-dependent dermal cell survival or proliferation, we performed TUNEL assay and examined Ki67 expression in Prx1-cre; Smo ${ }^{f l / n}$ skin. We did not detect increased cell apoptosis in the mutant dermis at either E17.5 or P0 (Supplemental Fig. S2; data not shown). We observed the presence of TUNEL ${ }^{+}$cells in the outer layer of the epidermis, which nicely served as an internal positive control for the assay. We also did not detect a change in Ki67 expression in either the epidermis or dermis of Prx1cre; Smo ${ }^{f l / n}$ skin at either E17.5 or P0 (Supplemental Fig. S2; data not shown). The hair follicle epithelia of both the mutants and controls show comparable Ki67-positive staining, whereas the DC and DP cells were Ki67-negative. Similar findings were seen using anti-phospho-H3 (P-H3) staining. At E18.5, we detected 3.1 and 3.4 P-H3-positive nuclei per dermal view $(P>0.7)$, respectively, in the wild type and mutant. At P0, there were 0.9 and 1.1 P-H3positive nuclei per dermal view $(P>0.7)$, respectively, in the wild type and mutant. In summary, the loss of DCs was not due to cell death or compromised cell growth of the DC cells or the interfollicular dermis. Furthermore, degeneration of DCs did not immediately lead to an epithelial proliferation defect.

\section{Dermal Smo is required to regenerate hair follicles in a hair reconstitution assay}

To confirm and specifically show that the hair follicle morphogenesis defects of dermal Smo knockouts were not due to a systemic effect in the mesenchyme during embryonic skin development and to facilitate further analysis of signaling cross-talk, we developed a hair regenerative genetic assay (Fig. 3, top panel; Materials and Methods). In this modified hair reconstitution assay (Lichti et al. 1993, 2008; Weinberg et al. 1993), we established cell type-specific gene functions during hair follicle formation by expressing shRNAs/cDNAs in the dissociated neonatal dermal cells via lentivirus (Ventura et al. 2004) prior to regenerating the hair follicle in a silicon chamber.

We aimed to examine hair regenerated with primary neonatal dermal cells treated with a Smo shRNA lentivirus and compared it with Prx1-cre; Smo ${ }^{\text {fl/n }}$ skin. Smo shRNA-treated primary dermal cells successfully reduced $>90 \%$ of Smo RNA and protein expression (Fig. 3G) and Shh signaling (Figs. 3H, 4C). Despite strong knockdown, cell survival and proliferation were not affected in these primary dermal cells (Supplemental Fig. S3H,I). Using TUNEL staining, both control and Smo knockdown dermal cells display a low apoptotic ratio; Ki67 staining revealed a slight but insignificant proliferation decrease in Smo knockdown dermal cells after serum starvation. Thus, similar to DCs in Prx1-cre; Smo ${ }^{f l / n}$ skin, Smo knockdown in primary dermal cells affects Shh signaling without strong effects on proliferation or cell death.

We combined Smo knockdown dermal cells with freshly isolated wild-type neonatal primary epidermal cells and applied the cell mixture onto nude mice to regenerate hair. At 3 wk, both control and Smo knockdown grafts had graft areas with comparable sizes (Fig. 3A,D). While control grafts displayed robust hair growth, dermal Smo knockdown grafts showed reduced hair growth (Fig. 3A,B,D,E). Histological analysis revealed that dermal Smo knockdown grafts contained threefold fewer hair follicles that were delayed in development (Fig. 3B,C,E,F; data not shown). In control grafts, $>90 \%$ of the hair follicles reached or exceeded the mature stage, stage 6, while in knockdown grafts, $<50 \%$ of the hair follicles were at stage 6 (Fig. 3I). Approximately $47 \%$ of the knockdown grafts' hair follicles attained stage $3-5$, while $7 \%$ were at stage $1-2$. In contrast, in control grafts, all hair follicles developed past stage 1-2. Thus, hair follicle development in knockdown grafts showed early growth arrest. Although growth is delayed, the regenerated hair follicles in dermal Smo knockdown grafts have normal morphology (Fig. 3C,F) and express normal epithelial and DP markers (Supplemental Fig. S3A$\mathrm{D}, \mathrm{E}^{\prime}, \mathrm{F}^{\prime}$; data not shown).

The hair follicle regeneration defects are similar to, although milder than, the Prx1-cre; $S m o^{f l / n}$ hair follicle 


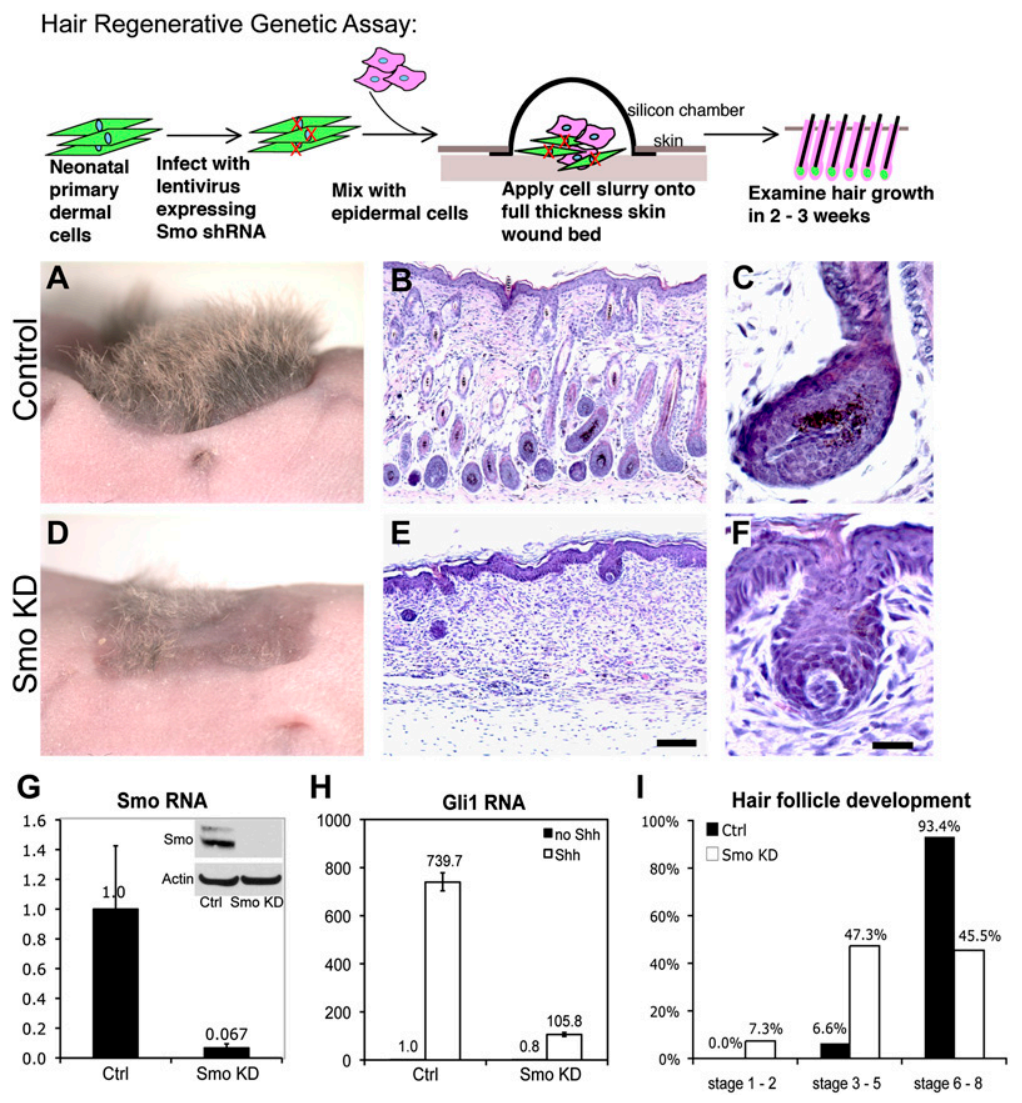

Figure 3. Smo knockdown in neonatal dermal cells reduces hair follicle regeneration in a modified hair reconstitution assay. (Top) Schematic demonstration of hair regenerative genetic assay using Smo knockdown primary dermal cells and untreated fresh epidermal cells, both from neonatal mice. $(A, D)$ Lateral view of 3 -wk regenerative hair grafts. $(A)$ Control hair grafts generated from dermal cells infected with lentiviral vector expressing a nonspecific shRNA. $(D)$ Dermal-specific Smo knockdown hair grafts. $(B-F)$ Hematoxylin-eosin staining of graft sections from control $(B, C)$ and Smo knockdown $(E, F) . C$ and $F$ are magnified images showing hair follicle morphology. $(C)$ Control hair follicles are fully mature (stage 6 and later), with compact DPs, melanin deposits, and hair shaft. $(F)$ Slower-developed hair follicle (stage 4) with normal morphology, except a smaller DP in the dermal Smo knockdown hair graft. $(G, H)$ Quantitative PCR of Smo knockdown neonatal primary dermal cells. Smo shRNAs efficiently reduce Smo RNA and protein expression level $(G)$ and Glil induction by Shh $(H)$. $(I)$ Development stages of hair follicles in control and dermal Smo knockdown hair grafts. A minimum of 50 hair follicles was counted for each condition. (Ctrl) Control infection with lentiviral vector alone or with a nonspecific shRNA; (Smo KD) Smo knockdown. Bars: $B, E, 100 \mu \mathrm{m}_{;}, C, F, 20 \mu \mathrm{m}$. development defects. One explanation is due to dermal chimerism in the regeneration assay. The origin of the regenerated hair follicles was confirmed with a $\beta$-galactosidase or GFP marker using Rosa26- or GFP-infected cells, respectively, as donors (Supplemental Fig. S3E-F"; data not shown). The GFP marker was coexpressed from the lentivirus vector that produced the shRNA /Ventura et al. 2004), thus allowing us to confirm that Smo knockdown dermal cells persist in the hair grafts (Supplemental Fig. S3E-F"). However, we also observed a small degree of chimerism of $\mathrm{GFP}^{+}$and $\mathrm{GFP}^{-}$cells in the DPs with Smo knockdown (Supplemental Fig. S3G), indicating that there are uninfected escapers. These data reinforce the need for dermal Smo function for hair follicle progression and demonstrate the reliability of our hair regeneration genetic assay.

Smo is required for the expression of a subset of DP signature and signaling genes

To understand the mechanism for how dermal Smo regulates DC maturation, we first examined the expression patterns of a few candidate DP markers and signaling molecules in control and Smo knockdown primary dermal cells using quantitative PCR. We showed that several genes required Smo to maintain expression, but in cell culture they were not Shh-responsive. These included Noggin, Fgf10, and AKP2 (Fig. 4A).

To identify Shh-responsive DP genes, we performed expression profiling for Shh-regulated genes in control and
Smo knockdown primary dermal cells. Overall, we detected 272 genes whose Shh response differed in control and Smo knockdown dermal cells. These genes included both signaling molecules and matrix proteins, but notably lacked core cell cycle and apoptotic genes (data not shown). To define the Shh-regulated DP signature, we compared these 272 genes with the previously published DP signature gene list (Rendl et al. 2005). As shown in the Venn diagram (Fig. 4B), of the 182 genes previously described as a DP signature, only $19(10 \%)$ were Smo-dependent and Shh-responsive, including known hedgehog target genes Ptch1 and Hhip. Interestingly, the expression of many key genes such as PDGF receptor $\alpha$ (Pdgfra) and Wnt5a were independent of Smo expression (Fig. 4A). Of the 19 Shh-responsive DP genes, six are transcription factors, and nine are membraneassociated receptors or secreted factors. We also identified Wif1, a secreted protein with Wnt-binding and inhibitory ability (Hsieh et al. 1999), to be highly responsive to Shh. Consistent with our finding, Wif1 has been shown as a stromal Hh response gene (Yauch et al. 2008). In addition to previously reported $\mathrm{Hh}$ target genes, we found that the transcription factor Sox 18 was also Shh-responsive. Sox 18 (Pennisi et al. 2000; Irrthum et al. 2003; James et al. 2003; Cermenati et al. 2008), along with another Sry-related HMG box family protein, Sox2 (Biernaskie et al. 2009; Driskell et al. 2009), appears to regulate hair type fate determination. We confirmed the expression differences of the Shh-regulated DP signatures using quantitative PCR (Fig. 4C; data not shown). This focused effect of Smo knockdown 
A. Basal expression of DP genes

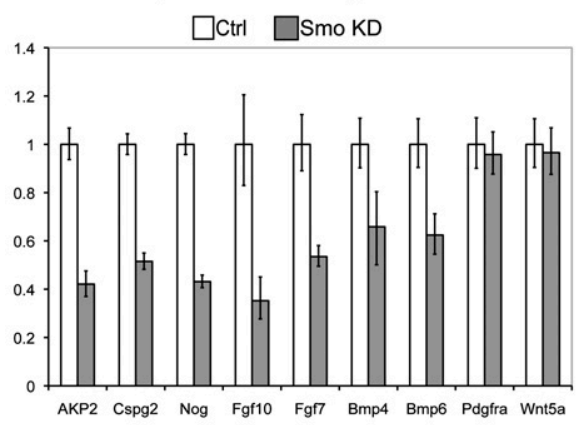

C. Shh induced DP genes

$\square$ Ctrl $\square$ Smo KD
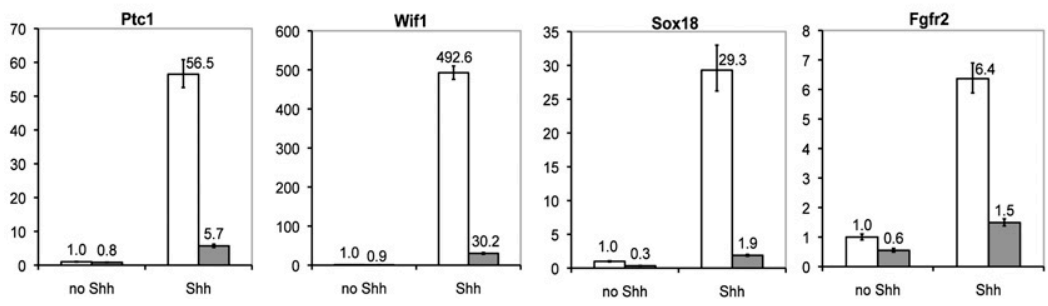

Figure 4. Dermal Smo regulates expression of a subset of DP signature genes. (A) Basal expression of a number of DP signature genes in Smo knockdown (Smo KD) neonatal mouse primary dermal cells at P0. Only a subset of these DP signature genes exhibited decreased expression with Smo knockdown, including AP (AKP2) and Noggin. (B) Venn diagram constructed from DP signature gene list and microarray data of Shhresponsive genes in control and Smo knockdown dermal cells. Expression of a limited number of DP signature genes was Shh-regulated. Those genes are listed in tabular form. $(C)$ Verification of Shh-induced DP genes using quantitative PCR. $(A, C)$ Representative data out of three experiments are shown. Error bars indicate SD. (Ctrl) Control infection with lentiviral vector alone or with a nonspecific shRNA; (Smo KD) Smo knockdown. on DP signatures is consistent with the idea that dermal Smo plays specific functions in maintaining DP cell identity, DP maturation, and/or signaling.

\section{Dermal Shh signaling is required to maintain expression of DC Sox2, Sox18, and Noggin}

To confirm dermal Shh/Smo-regulated gene expression in vivo, we examined the in vivo expression of several signaling molecules and transcription factors in Prx1-cre; Smo ${ }^{f 1 / n}$, as defined by expression in Syndecan $-1^{+}($Syn 1$)$ (Richardson et al. 2009) or $\mathrm{P}^{2} 5 \mathrm{NTR}^{+}$DC cells. We found that the expression of three factors-Sox2, Sox 18, and Nogginwas markedly reduced in Smo knockout DCs in Prx1-cre; $\mathrm{Smo}^{f l / n}$ at E17.5 (Fig. 5C; Supplemental Fig. S5). In contrast, we confirmed that the expression of other DP-associated signaling proteins, such as PDGFR $\alpha$ and FGF10, was unchanged (data not shown). In addition to Syn1 and P75NTR, the expression of other DP-associated cell surface or extracellular matrix components, including Versican, also remained unchanged in vivo (data not shown). Therefore, the decreased expression of Sox2, Sox18, and Noggin is a specific outcome of Smo loss of function instead of due to DC degeneration.

We asked whether the three genes could also be induced by Gli1, the transcription factor that mediates Shh signal transduction. Using retrovirally expressed human Gli1 (hGli1), all three genes were Gli1-inducible, with Noggin, Sox18, and Sox2 demonstrating varying levels of Gli1 induction in primary dermal cells (Fig. 5A). We investigated the relative time of induction of the three genes and found that endogenous Glil (mGlil) levels elevated immediately, reached their peak within $20 \mathrm{~h}$, and then began to subside. In contrast, while Sox 18 levels elevated from $\sim 20 \mathrm{~h}$ after hGlil viral infection, reached their peak later after $40 \mathrm{~h}$, and then persisted, expression of Sox2 and Noggin elevated at the same time but was far more transient (Fig. 5B). Thus, Glil overexpression is sufficient to induce Sox2, Sox18, and Noggin, while their induction is a secondary or indirect response compared with the fast and direct response of endogenous Gli1.

Since Sox 2 and Sox 18 are transcription factors whose expression mirrors that of Noggin, we asked whether dermal Shh signaling indirectly maintains Noggin expression via Sox2 or Sox18. Using lentivirus to express either the Sox proteins or shRNAs, we found that neither Sox 2 nor Sox 18 overexpression increased Noggin expression, nor did removal of Sox 2 or Sox18 affect Glil induction on Noggin (Supplemental Fig. S4). Thus, dermal Shh signaling regulates Sox2/ Sox18 and Noggin via independent pathways.

\section{Noggin partially rescues dermal Smo knockdown hair regeneration defects by increasing epithelial Shh expression}

To better understand the functional relationship between Smo and Smo-responsive genes, we asked whether any of the three identified genes could complement the loss of Smo in dermal cells in the hair reconstitution assay. We adapted the lentivirus used to generate shRNA and cloned the tested gene into the lentiviral vector expressing the Smo hairpin (Ventura et al. 2004). Thus, we simultaneously expressed the tested gene and the Smo hairpin from the same vector. If the gene functions downstream 


\section{A. Induction by ectopic Gli1}
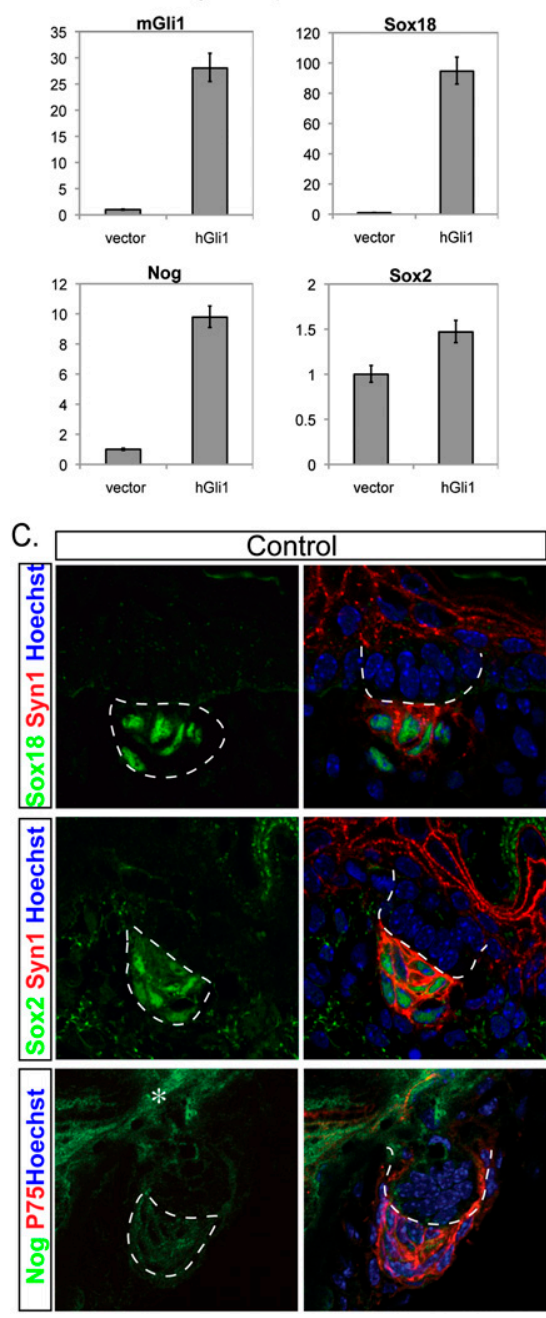

\section{B. Induction time course}
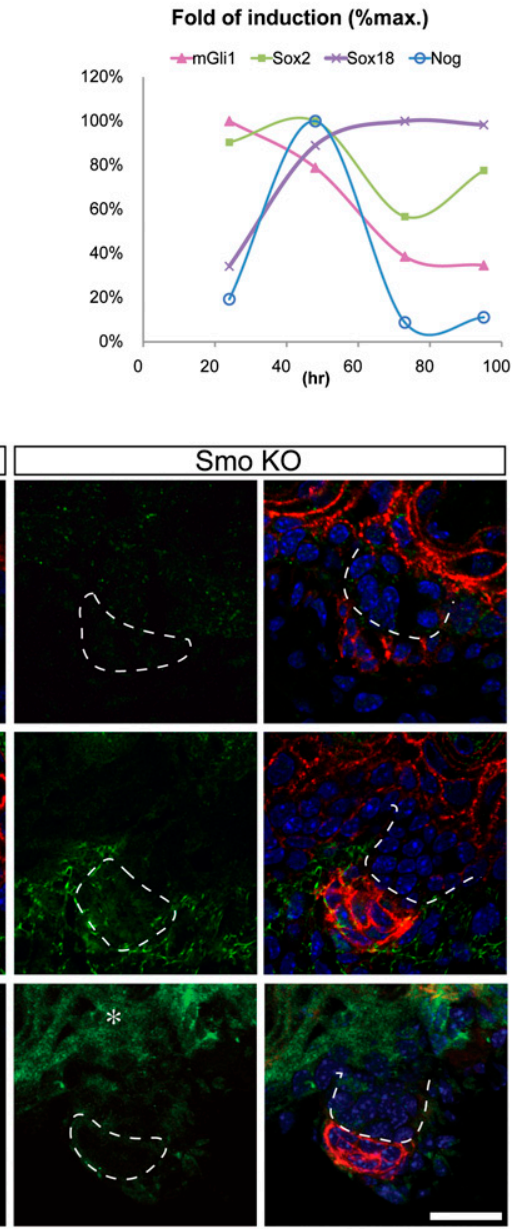

Figure 5. Dermal Shh signaling regulates the expression of Sox2, Sox18, and Noggin. $(A)$ Overexpression of hGlil-induced Noggin, Sox18, and Sox2. (Vector) Control cells infected with a retroviral vector expressing GFP; (hGli1) induced cells infected with the same retroviral vector but expressing a hGlil gene. Representative data out of three experiments are shown. Error bars indicate SD. (B) Temporal induction profile of mouse Gli1 (mGli1), Sox2, Sox18, and Noggin. mGlil induction reaches maximum before all three other genes. Noggin and Sox2 induction was transient, while Sox18 induction persisted for some time. $(C)$ In vivo expression of Sox18, Sox2, and Noggin was reduced in Prx1-cre; Smo ${ }^{f 1 / n}$ DCs. Stage 2 hair germs from E17.5 ventral skin were labeled with Syndecan1 (Syn-1) or P75NTR and the indicated DP signature molecules. Sox18 and Sox 2 nuclear signal as well as Noggin membrane-like signal were lost in Prx1-cre; Smo ${ }^{f 1 / n}$ (Smo KO). Quantification of DC Noggin signal intensity confirmed more Noggin in control (152.057) than in the mutant (73.325). Nonspecific signal is detected in the epidermis in both the control and mutant (asterisks). Dashed lines demarcate DCs (closed circular shape) and hair germ epithelium (opened U-shape). Bar, $20 \mu \mathrm{m}$. from Smo, then expression of the gene simultaneously with the Smo knockdown should either restore hair follicle number or allow maturation through additional developmental stages.

We found that Noggin, but not Sox 2 or Sox18, could partially rescue loss of Smo function (Fig. 6; data not shown). Both Noggin control (shCtrl+Nog) and Noggin Smo knockdown (shSmo+Nog) grafts displayed similar hair follicle numbers, but their hair follicles were enlarged, consistent with the K14-Noggin overexpression phenotype (Fig. 6C,D; Sharov et al. 2009). We confirmed reduction in Smo expression in the dermal cells using quantitative PCR (Fig. 6F). When compared with non-Noggin control grafts (shCtrl+GFP), Noggin-expressing grafts also display an insignificant mild delay in hair follicle maturity (Fig. 6A,C,D). Approximately $70 \%$ of the hair follicles were at stage 6 , while $\sim 25 \%$ of the hair follicles remained at stage $3-5$ (Fig. 6E). However, this is in contrast to the sparse and delayed hair follicle growth observed in Smo knockdown grafts (Fig. 6B). Hair follicles formed in both Noggin and Noggin-Smo knockdown grafts resulted in increased hair follicle numbers and maturity (Fig. 6C,D). We found that significantly more stage 6 hair follicles were generated in Noggin-Smo knockdown grafts than in Smo knockdown grafts (Fig. 6E). Thus, compared with dermal Smo knockdown regenerative hair grafts, Noggin overexpression was able to rescue the progression of hair follicle development delayed by Smo knockdown to past stage 2 and progress to stage 6 . This indicates that Noggin can function downstream from Smo in early hair follicle down-growth.

Studies in Shh signaling regulation on limb bud development have shown that the mesenchymal Shh source induces epithelial signaling to maintain mesenchymal Shh expression (Niswander et al. 1994). Furthermore, Noggin beads injected in postnatal mouse back skin expanded Shh expression throughout the hair follicle matrix (Botchkarev et al. 2001). We asked whether dermal Noggin overcomes Smo partial loss of function by enhancing epithelial Shh signal expression, thereby permitting additional Shh to act on adjacent DPs. Using in situ hybridization, we showed that, in control and Smo knockdown hair follicles, Shh mRNA is asymmetrically localized within growing follicles in the hair matrix (Fig. 7A,B; Oro and Higgins 2003). In contrast, in dermal Noggin-expressing hair grafts, Shh 

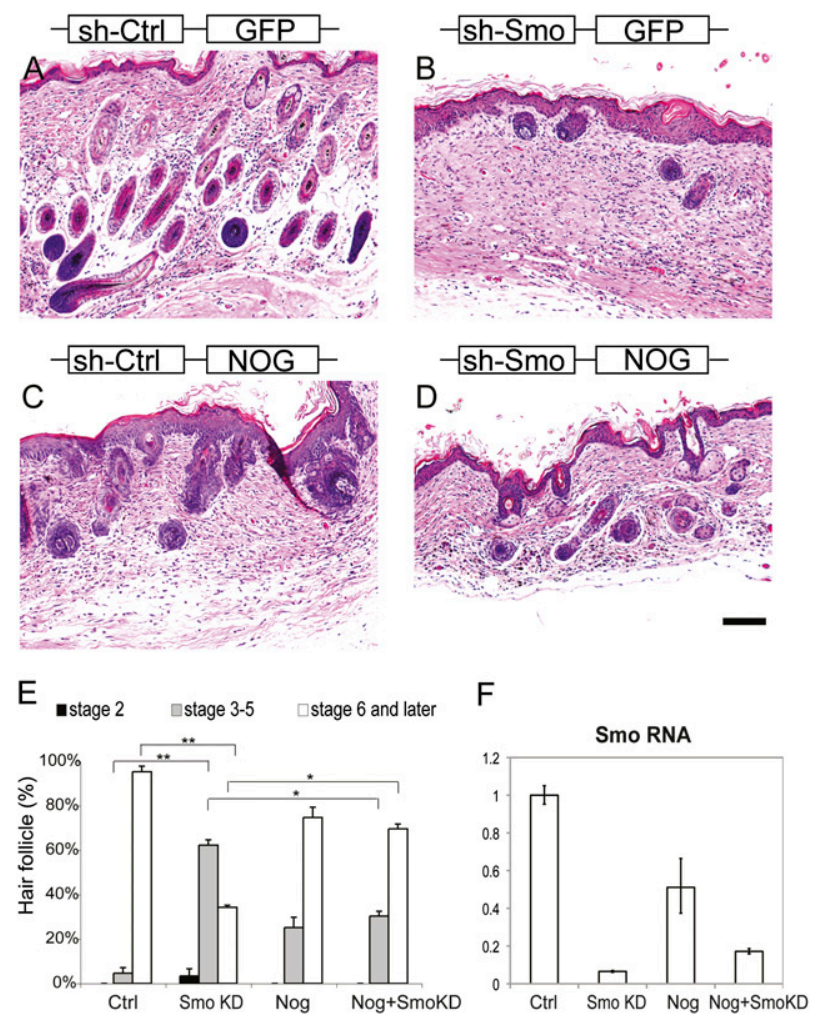

Figure 6. Noggin expression in dermal cells alleviates Smo knockdown hair regeneration defects. $(A-D)$ Hematoxylin and eosin staining of graft sections of control $(A)$, Smo knockdown $(B)$, Noggin overexpression with a nonspecific shRNA (sh-Ctrl) $(C)$, and Noggin overexpression with Smo knockdown $(D)$. In grafts with Noggin overexpression, more hair follicles were formed than in Smo knockdown grafts, and these hair follicles were significantly more advanced in development than in Smo knockdown grafts. $(E)$ Quantification of hair follicle development stages. Two to four grafts were counted per condition. $\left({ }^{\star}\right)$ $P<0.005 ;\left.\right|^{\star \star} \mid P<0.0005$. Error bars indicate SEM. Total hair follicle numbers counted for control (Ctrl), Smo knockdown (Smo KD), Noggin with nonspecific shRNA (Nog), and Noggin with Smo knockdown (Nog+SmoKD) are 207, 98, 103, and 130, respectively. (F) Quantitative PCR for Smo RNA expression of the primary dermal cells used in the hair regenerative genetic assay. Bar, $100 \mu \mathrm{m}$.

mRNA expression domains were expanded to both sides of the hair matrix or throughout the hair follicle epithelium (Fig. 7C). Shh protein expression shows patterns similar to Shh mRNA (Fig. 7D-F), with a markedly increased total number of Shh-producing cells present in the matrix. The observed ratio of $\mathrm{Shh}^{+}$cells to matrix cells was also significantly increased in Noggin-expressing hair grafts (Fig. 7G), indicating that Noggin affected Shh expression and not just the number of matrix cells. Moreover, in these Nogginexpressing grafts, we observed increased numbers of DP cells based on AP staining (data not shown). These findings suggest that Noggin enhances epithelial Shh expression during hair follicle development, forming a Noggin-Shh signaling loop, thereby facilitating hair follicle regeneration despite Smo knockdown in the dermal cells.

\section{Discussion}

Despite the importance of signaling between the mesenchyme and overlying epithelium, the contribution of key factors during organ development remains poorly understood. Previously, genes have been identified to be specifically expressed in the DP during hair follicle morphogenesis, but individual contributions to the dermal signaling in relation to the epithelium have been largely unexplored. Using mouse genetics and hair reconstitution assays, we showed that Shh acts directly on the DC during hair follicle morphogenesis to maintain DC cell identity and/or maturation. Shh action on the dermal compartment maintains its own expression through inducing Noggin in the DC. Our finding that Shh/Smo controls a small subset of DP signature genes without altering dermal proliferation, a prominent feature of its action on the epithelium, illustrates how divergent actions of a morphogen on different cell populations within the same tissue are required for proper morphogenesis.

Our genetic studies provide strong support for a direct role for Smo in the DC. Prx1cre; Smo ${ }^{f / n}$ stage 2 hair follicles phenocopy those in Shh- and Gli2-null mice as well as those lacking intraflagellar transport protein 88 (IFT88) in the dermis (Lehman et al. 2009), while dermal Ift88 knockout also displays a DC cell reduction phenotype. IFT88 is integral in the formation of the primary cilium, a structure known to facilitate Shh signaling. While many signaling pathways require the cilium for proper function, the similarity of the Smo loss of function to that of Ift 88 provides strong support that Shh signaling is the primary pathway transduced in dermal cells via primary cilia. Moreover, the

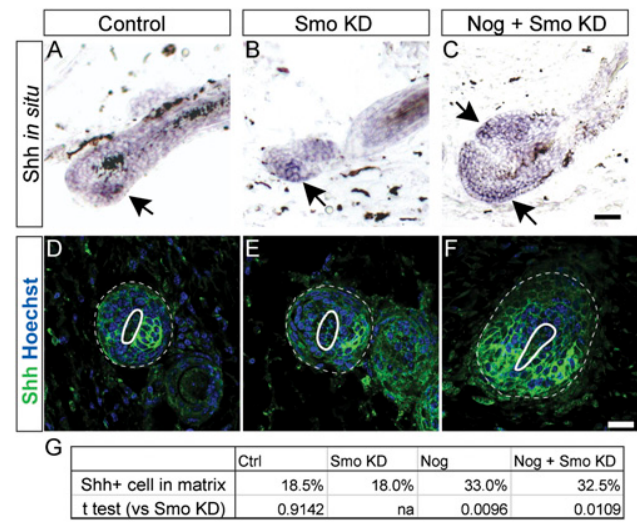

Figure 7. Noggin overexpression increases epithelial Shh expression. $(A-C)$ Shh mRNA in situ hybridization showing Shh expression (arrows) in regenerative hair grafts. Increased Shh expression domain was detected in the hair follicles from Noggin-overexpressed grafts. ( $D-F)$ Shh immunostaining (green) confirms an increased Shh protein expression in Noggin-overexpressed hair follicles. $(A, D)$ Control. $(B, E)$ Smo knockdown (Smo KD). $(C, F)$ Noggin with Smo knockdown (Nog+Smo KD). $(A-C)$ Longitudinal view of hair follicles. $(D-F)$ Cross-sectional view of hair follicles. Solid circles demarcate the DPs. Dashed circles demarcate the hair follicle epithelium. Bars, $20 \mu \mathrm{m} .(G)$ Statistical analyses of $\mathrm{Shh}^{+}$cell per matrix cell. Noggin expression significantly induces the number of cells expressing Shh. 
observation in both studies of transient increases in epidermal Ptch1 staining (Fig. 1K) suggests an inhibitory role of the DP on overlying epidermal hedgehog responsiveness. This likely arises from a transient increase in the Shh ligand due to less binding with the DP-and thus more availability for epithelial receptors (Gritli-Linde et al. 2007) — or from an increased sensitivity of the epithelium to the ligand. Consistent with the latter inhibitory role, ectopic Shh target gene induction and BCC formation appear most efficient in interfollicular epithelium not in contact with a mature DP (Youssef et al. 2010).

A previous report examining Gli2-null animals showed that epithelial Gli2 activator rescues early hair follicle number and development in Gli2- but not Shh-null skin and argued against a role for dermal Gli2 function (Mill et al. 2003). Thus, whereas Gli2 functions as the main mediator for epithelial Shh signaling, there is likely a Gli2-independent Shh-dependent mechanism in the DP. Consistent with this model is our demonstration that the early condensate forms but is not maintained in Smo knockout dermal cells. Our data extend the action of ShhGli2 on early stage 2 hair germ formation in the epithelium to include a Smo-dependent, Gli2-independent late stage 2 maintenance of the DC/DP (Supplemental Fig. S6). This is also consistent with our finding that germ stage epithelial proliferation is normal in our dermal Smo knockout mutants.

Two possible mechanisms explain dermal Shh signaling action on maintaining the DC. Shh could act as a retention signal that blocks migration, keeping the early DC in close proximity with the developing hair germ, while other epithelial morphogens control DC/DP cell fate. Consistent with this model, Shh plays a guidance role in directing midline axon migration (Charron et al. 2003). Alternatively, Shh could maintain DC/DP cell fate and maturation through signaling, while other epithelial morphogens provide a DC/DP retention signal. Our results favor the second model because Smo knockout hair follicles lose Sox2, Sox18, and Noggin but not Syn1 and P75NTR expression before the loss of the DC aggregation. Additionally, attempts to demonstrate Shh effects on dermal cell migration have thus far been unsuccessful (data not shown). It is unlikely that Shh acts on the DC/ DP to actively repress epithelial gene expression in the dermis, as the Shh-repressed gene list does not overlap with previously published lists for melanocytes, the matrix, or the outer root sheath (Rendl et al. 2005). Interestingly, forced expression of Shh during feather bud morphogenesis does result in increased dermal condensation in part through induction of the adhesion molecule NCAM (Ting-Berreth and Chuong 1996). However, our observation that the expression of adhesion molecules changes only after loss of other Smo-regulated genes supports a more indirect role for Smo in regulating adhesion.

Apart from DC cell identity and maturation, Shh also contributes to its own maintenance through the induction of Noggin. Previous studies of noggin knockout corroborate the relationship, as Shh levels in noggin knockout gradually disappear (Botchkarev et al. 1999, 2002). Our findings are similar to Shh's role in limb bud outgrowth, where Shh acts on the zone of polarizing activity and functions with FGF and the BMP antagonist Gremlin to reinforce the timing of outgrowth (Niswander et al. 1994; Zuniga et al. 1999). Recent studies in the limb suggest that mutually reinforcing and repressive feedback loops with Shh explain limb bud outgrowth. In the developing hair, Shh and Noggin provide a key positive loop (Botchkarev et al. 2001, 2002). The observation that BMP6 is required for maintaining DP hair inductive function (Rendl et al. 2008) puts forth the tantalizing hypothesis that Noggin and BMP6 may constitute part of a negative feedback loop regulating hair outgrowth. As Shh alone does not appear to induce Noggin expression directly (our unpublished data), and Sox2 or Sox18 is not involved in the regulation of Noggin expression, we postulate that additional signals are involved to regulate the duration of outgrowth. One such factor may be PDGF, which was shown to work together with Shh to increase Noggin expression in vitro (Gao et al. 2008).

Studies of epithelial-derived Shh effects on dermal function may have relevance to human cancer. Recent studies of Shh pathway activation indicate that inappropriate pathway activity underlies up to $25 \%$ of human cancers. Frequently, aggressive pancreatic, colon, and smallcell lung cancers up-regulate hedgehog ligands (Indian or Sonic hedgehog) with hedgehog target genes induced in the surrounding stroma instead of the tumor epithelium (Rubin and de Sauvage 2006; Yauch et al. 2008). Interestingly, many BMP antagonists are found in the stroma of these cancers, and our data suggest that they may be reinforcing tumor Shh production to maintain cancer growth. Disruption of this proposed signaling loop may have therapeutic potential (Sneddon et al. 2006).

\section{Materials and methods}

\section{Mice}

All procedures involving animal handling conformed to the Stanford International Union for Pure and Applied Chemistry. Neonatal mice for hair reconstitution grafts were from the crosses of ROSA26 (Friedrich and Soriano 1991) or C57BL/6 (both are from The Jackson Laboratory) males with CD1 (Charles River) females. We used $\mathrm{Ncr}: \mathrm{Nu} / \mathrm{Nu}$ females (Taconic) as graft recipients. Smo ${ }^{f l / f 1}\left(\mathrm{Smo}^{\text {tm2Amc }} / \mathrm{J}\right)$ (Long et al. 2001) and Prx1-cre [B6.Cg-Tg(Prrx1-cre)1Cjt/J] (Logan et al. 2002) are from The Jackson Laboratory. $S \mathrm{mo}^{n /+}$ is a kind gift from Dr. Philip Beachy's laboratory (Ma et al. 2002). Ptc1-lac $Z^{+/-}$is a kind gift from Dr. Matthew Scott's laboratory (Goodrich et al. 1997). ROSA26-EYFP [B6.129X1-Gt/(ROSA) 26Sortml(EYFP)Cos/J] (Srinivas et al. 2001) is a kind gift from Dr. Mark Krasnow's laboratory.

\section{Lentiviral shRNA construction and virus production}

We followed the protocol from Tyler Jacks's laboratory (Ventura et al. 2004; http://web.mit.edu/jacks-lab/protocols/pSico.html) to generate lentiviral Smo shRNA. Putative Smo hairpin sequences were designed using the pSICOLIGOMAKER program created by Dr. Andrea Ventura and cloned into the pSicoR-CMVGFP vector. We tested five Smo shRNAs and used the one with the strongest knockdown effect without affecting cell survival. The core sequence of the Smo shRNA used in hair reconstitution assay is GAGAAAAGCCTTGTTTGAAGAAATATGAACAG 
CAA. The lentiviral system for producing Sox 2 shRNA and Sox 18 shRNA is pLKO.1 (Open Biosystems). Lentivirus was generated in $293 \mathrm{~T}$ cells by cotransfecting $\Delta 8.9$ and VSVG together with the shRNA vector. Retrovirus with hGlil expression was collected from a stable phoenix cell clone.

\section{Primary dermal cell culture and viral transduction}

Primary dermal cells were isolated from mouse skin within $3 \mathrm{~d}$ of birth as previously described (Weinberg et al. 1993; Lichti et al. 2008). We plated the primary dermal cells in Amniomax C-100 medium (GIBCO Invitrogen) to maintain the DP cell population (Rendl et al. 2005). Primary dermal cells were infected a day after plating, at $50 \%$ confluence, using $8 \mu \mathrm{g} / \mathrm{mL}$ polybrene as carrier.

\section{Quantitative PCR and Western blot}

To isolate E17.5 dermal RNA, E17.5 ventral skin was incubated in dispase for $1 \mathrm{~h}$ at $37^{\circ} \mathrm{C}$, and dermis was collected in RNALater (Qiagen). We then extracted the dermal RNA with the RNeasy fibrous tissue kit (Qiagen). We performed one-step quantitative RT-PCR using SYBR Green (Stratagene) and applied the $-2^{\Delta \Delta C t}$ method from the MxPro comparative calibration program to calculate relative RNA amount using GAPDH as a normalizer. Protein extract was prepared in a modified RIPA method, and Western blotting was performed as previously described (Rohatgi et al. 2007).

\section{Microarray analyses}

RNA was amplified one round, and Shh induced and uninduced samples were labeled with Cy5 and Cy3, respectively, and competitively hybridized to microarrays. Array hybridization of the Mouse Exonic Evidence-Based Oligonucleotide (MEEBO) array was performed at the Stanford Functional Genomics Facility (http:// microarray.org/sfgf/meebo.do). Three biological replicates were used. Differential Shh-responsive genes were identified using the SAM application (Tusher et al. 2001). Shh-responsive DP signatures were identified by comparing them with the DP signature gene list (Rendl et al. 2005) using BioVenn (Hulsen et al. 2008). Statistical analysis was performed using Fisher's exact test.

Hair reconstitution assay using short-term cultured,

virus transduced dermal cells

In each experiment, we prepared three grafts per treatment. We collected Smo knockdown dermal cells $1 \mathrm{~d}$ after infection and combined them with uninfected wild-type epidermal cells at 10 million cells each to generate one hair reconstitution graft. The two cell types were applied as a cell slurry of $100 \mu \mathrm{L}$ onto a $1-\mathrm{cm}$ diameter full-thickness skin wound on the back of a nude mouse. The graft site was prepared and covered with silicon chambers similar to the Lichti et al. (2008) protocol, except that we stitched the silicon chambers (F2 U; Renner GMBH) and used a 23-gauge needle to apply cell slurry. A week after grafting, we removed the chambers and put on a bandage over the graft sites for another $3 \mathrm{~d}$. Hair growth began to show on control grafts from day 16 onward. Control grafts with either pSicoR-CMV-GFP vector alone or one that carries a nonspecific shRNA resulted in similar hairy grafts. We collected the grafts at 3 wk after grafting.

\section{Histomorphometry and X-gal staining}

Analysis of hair follicle development was performed according to the staging criteria described previously (Paus et al. 1999). Longitudinal hair follicle sections were separated by at least 40 $\mu \mathrm{m}$ to avoid double-counting the same hair follicles. At least 40 hair follicles were counted per animal, using wild-type littermates as control. For hair grafts, two to four grafts per treatment were counted. For the genetic mouse model, three animals per genotype were counted. X-gal staining was performed on dissected E18.5 mouse skin after 4\% paraformaldehyde fixation. We then embedded the stained skins in OCT and used $10-\mu \mathrm{m}$ sections for analyses. Two-tailed unpaired Student's $t$-test was used for statistical analysis.

\section{Immunostaining}

For immunocytochemistry, we fixed cells with $4 \%$ paraformaldehyde, and permeabilized cells with $0.25 \%$ Triton X-100. For tissue immunofluorescence in frozen sections, we prepared 6- to $12-\mu \mathrm{m}$ sections and post-fixed the sections in either $4 \%$ paraformaldehyde or cold acetone, depending on the antibodies used, then proceeded to serum blocking and antibody incubation. For tissue immunofluorescence in paraffin sections, $6-\mu \mathrm{m}$ sections were prepared and treated with $10 \mathrm{mM}$ citrate or $1 \mathrm{mM}$ EDTA for antigen retrieval. Immunofluorescence label images were captured with a Zeiss confocal microscope LSM 510 with Ti:Sapphire laser for two-photon excitation or a Zeiss Axiovert microscope with Openlab software. ImageJ software was used to quantify signal intensity using the original LSM images captured under the same settings.

The following primary antibodies were used: anti-Ki67 (1:200; Thermo Fisher Scientific), anti-K17 (1:3000; gift from Pierre Coulombe), anti-K14 (1:1500; Covance), AE13 (1:50; Abcam), anti-P-cadherin (1:50; Invitrogen/Zymed), anti-Versican (1:400; Millipore), anti-CD133 (1:50; eBiosceince), anti-P75NTR (1:200; Abcam), anti-Syndecan-1 (1:200; Pharmingen), anti-Sox2 (1:75; Santa Cruz Biotechnology), anti-Sox18 (1:100; Santa Cruz Biotechnology), anti-Shh (1:50; Santa Cruz Biotechnology), goat antiNoggin (1:40; Santa Cruz Biotechnology) (Supplemental Fig S5), rat anti-Noggin RP57-06 (1:200; Regeneron Pharmaceuticals, kind gift from Richard Harland laboratory) (Fig. 5), and anti-Smo (1:250; kind gift from Matthew Scott laboratory) (Rohatgi et al. 2007). Alexa Fluor 488/594/647-conjugated secondary antibodies (Invitrogen) were used at 1:400 dilution. Hoechst 33342 was used for nuclear counterstaining.

\section{AP staining, TUNEL assays, and in situ hybridization}

AP staining was performed on $10-\mu \mathrm{m}$ frozen sections that were fixed with $4 \%$ paraformaldehyde (using NBT/BCIP for detection) and counterstained with Hoechst 33342 to reveal nuclei. We performed a TUNEL assay according to the vendor's protocol (Roche), using 6- $\mu \mathrm{m}$ paraffin sections and proteinase $\mathrm{K}$ for antigen retrieval.

In situ hybridization was performed using frozen sections and a DIG-labeled riboprobe as previously described (Oro and Higgins 2003).

\section{Acknowledgments}

We thank Dr. Philip Beachy for generously providing the Smon/+ mice, and Drs. Tyler Jacks and Julien Sage for providing the lentivirus vector pSicoR-CMVGFP. We are grateful to Drs. Bing $\mathrm{Hu}$ and Paolo Dotto for advice on immunostaining; Dr. Matthew Scott for the anti-Smo antibody; Drs. Ljiljana Milenkovic and R. Tyler Hillman for advice on Smo Western blotting; and Drs. David Stafford and Richard Harland for their generous gift of the antiNoggin antibody. This work was supported by NIH R01AR046786 and R01 FAR052785, and the California Institute of Regenerative Medicine. 


\section{References}

Biernaskie J, Paris M, Morozova O, Fagan BM, Marra M, Pevny L, Miller FD. 2009. SKPs derive from hair follicle precursors and exhibit properties of adult dermal stem cells. Cell Stem Cell 5: 610-623.

Botchkarev VA, Botchkareva NV, Roth W, Nakamura M, Chen LH, Herzog W, Lindner G, McMahon JA, Peters C, Lauster R, et al. 1999. Noggin is a mesenchymally derived stimulator of hair-follicle induction. Nat Cell Biol 1: 158-164.

Botchkarev VA, Botchkareva NV, Nakamura M, Huber O, Funa K, Lauster R, Paus R, Gilchrest BA. 2001. Noggin is required for induction of the hair follicle growth phase in postnatal skin. FASEB J 15: 2205-2214.

Botchkarev VA, Botchkareva NV, Sharov AA, Funa K, Huber O, Gilchrest BA. 2002. Modulation of BMP signaling by noggin is required for induction of the secondary (nontylotrich) hair follicles. J Invest Dermatol 118: 3-10.

Cermenati S, Moleri S, Cimbro S, Corti P, Del Giacco L, Amodeo R, Dejana E, Koopman P, Cotelli F, Beltrame M. 2008. Sox 18 and Sox7 play redundant roles in vascular development. Blood 111: 2657-2666.

Charron F, Stein E, Jeong J, McMahon AP, Tessier-Lavigne M. 2003. The morphogen Sonic hedgehog is an axonal chemoattractant that collaborates with netrin-1 in midline axon guidance. Cell 113: 11-23.

Chiang C, Swan RZ, Grachtchouk M, Bolinger M, Litingtung Y, Robertson EK, Cooper MK, Gaffield W, Westphal H, Beachy PA, et al. 1999. Essential role for Sonic hedgehog during hair follicle morphogenesis. Dev Biol 205: 1-9.

Collins CA, Kretzschmar K, Watt FM. 2011. Reprogramming adult dermis to a neonatal state through epidermal activation of $\beta$-catenin. Development 138: 5189-5199.

Dahmane N, Lee J, Robins P, Heller P, Ruiz i Altaba A. 1997. Activation of the transcription factor Glil and the Sonic hedgehog signalling pathway in skin tumours. Nature 389: 876-881.

Driskell RR, Giangreco A, Jensen KB, Mulder KW, Watt FM. 2009. Sox2-positive dermal papilla cells specify hair follicle type in mammalian epidermis. Development 136: 28152823.

Driskell RR, Clavel C, Rendl M, Watt FM. 2011. Hair follicle dermal papilla cells at a glance. J Cell Sci 124: 1179-1182.

Enshell-Seijffers D, Lindon C, Kashiwagi M, Morgan BA. 2010a. $\beta$-Catenin activity in the dermal papilla regulates morphogenesis and regeneration of hair. Dev Cell 18: 633-642.

Enshell-Seijffers D, Lindon C, Wu E, Taketo MM, Morgan BA. 2010b. $\beta$-Catenin activity in the dermal papilla of the hair follicle regulates pigment-type switching. Proc Natl Acad Sci. 107: 21564-21569.

Estrach S, Cordes R, Hozumi K, Gossler A, Watt FM. 2008. Role of the Notch ligand Deltal in embryonic and adult mouse epidermis. J Invest Dermatol 128: 825-832.

Friedrich G, Soriano P. 1991. Promoter traps in embryonic stem cells: A genetic screen to identify and mutate developmental genes in mice. Genes Dev 5: 1513-1523.

Fuchs E, Horsley V. 2008. More than one way to skin. Genes Dev 22: 976-985.

Gao J, DeRouen MC, Chen CH, Nguyen M, Nguyen NT, Ido H, Harada K, Sekiguchi K, Morgan BA, Miner JH, et al. 2008. Laminin-511 is an epithelial message promoting dermal papilla development and function during early hair morphogenesis. Genes Dev 22: 2111-2124.

Goodrich LV, Milenkovic L, Higgins KM, Scott MP. 1997. Altered neural cell fates and medulloblastoma in mouse patched mutants. Science 277: 1109-1113.
Grachtchouk M, Mo R, Yu S, Zhang X, Sasaki H, Hui C, Dlugosz A. 2000. Basal cell carcinomas in mice overexpressing Gli2 in skin. Nat Genet 24: 216-217.

Greco V, Chen T, Rendl M, Schober M, Pasolli HA, Stokes N, Dela Cruz-Racelis J, Fuchs E. 2009. A two-step mechanism for stem cell activation during hair regeneration. Cell Stem Cell 4: 155-169.

Gritli-Linde A, Hallberg K, Harfe BD, Reyahi A, Kannius-Janson M, Nilsson J, Cobourne MT, Sharpe PT, McMahon AP, Linde A. 2007. Abnormal hair development and apparent follicular transformation to mammary gland in the absence of hedgehog signaling. Dev Cell 12: 99-112.

Handjiski BK, Eichmuller S, Hofmann U, Czarnetzki BM, Paus R. 1994. Alkaline phosphatase activity and localization during the murine hair cycle. Br J Dermatol 131: 303-310.

Hardy MH. 1992. The secret life of the hair follicle. Trends Genet 8: $55-61$.

Hsieh JC, Kodjabachian L, Rebbert ML, Rattner A, Smallwood PM, Samos CH, Nusse R, Dawid IB, Nathans J. 1999. A new secreted protein that binds to Wnt proteins and inhibits their activities. Nature 398: 431-436.

Hu B, Lefort K, Qiu W, Nguyen BC, Rajaram RD, Castillo E, He F, Chen Y, Angel P, Brisken C, et al. 2010. Control of hair follicle cell fate by underlying mesenchyme through a CSL-Wnt5a-FoxN1 regulatory axis. Genes Dev 24: 15191532.

Hulsen T, de Vlieg J, Alkema W. 2008. BioVenn-a Web application for the comparison and visualization of biological lists using area-proportional Venn diagrams. BMC Genomics 9: 488. doi: 10.1186/1471-2164-9-488.

Huntzicker EG, Estay IS, Zhen H, Lokteva LA, Jackson PK, Oro AE. 2006. Dual degradation signals control Gli protein stability and tumor formation. Genes Dev 20: 276-281.

Irrthum A, Devriendt K, Chitayat D, Matthijs G, Glade C, Steijlen PM, Fryns JP, Van Steensel MA, Vikkula M. 2003. Mutations in the transcription factor gene SOX18 underlie recessive and dominant forms of hypotrichosis-lymphedema-telangiectasia. Am J Hum Genet 72: 1470-1478.

Ito Y, Hamazaki TS, Ohnuma K, Tamaki K, Asashima M, Okochi H. 2007. Isolation of murine hair-inducing cells using the cell surface marker prominin-1/CD133. I Invest Dermatol 127: 1052-1060.

James K, Hosking B, Gardner J, Muscat GE, Koopman P. 2003. Sox 18 mutations in the ragged mouse alleles ragged-like and opossum. Genesis 36: 1-6.

Jamora C, DasGupta R, Kocieniewski P, Fuchs E. 2003. Links between signal transduction, transcription and adhesion in epithelial bud development. Nature 422: 317-322.

Karlsson L, Bondjers C, Betsholtz C. 1999. Roles for PDGF-A and sonic hedgehog in development of mesenchymal components of the hair follicle. Development 126: 2611-2621.

Kishimoto J, Burgeson R, Morgan B. 2000. Wnt signaling maintains the hair-inducing activity of the dermal papilla. Genes Dev 14: 1181-1185.

Lee J, Basak JM, Demehri S, Kopan R. 2007. Bi-compartmental communication contributes to the opposite proliferative behavior of Notch1-deficient hair follicle and epidermal keratinocytes. Development 134: 2795-2806.

Lehman JM, Laag E, Michaud EJ, Yoder BK. 2009. An essential role for dermal primary cilia in hair follicle morphogenesis. J Invest Dermatol 129: 438-448.

Lichti U, Weinberg WC, Goodman L, Ledbetter S, Dooley T, Morgan D, Yuspa SH. 1993. In vivo regulation of murine hair growth: Insights from grafting defined cell populations onto nude mice. I Invest Dermatol 101: 124S-129S. 
Lichti U, Anders J, Yuspa SH. 2008. Isolation and short-term culture of primary keratinocytes, hair follicle populations and dermal cells from newborn mice and keratinocytes from adult mice for in vitro analysis and for grafting to immunodeficient mice. Nat Protoc 3: 799-810.

Logan M, Martin JF, Nagy A, Lobe C, Olson EN, Tabin CJ. 2002. Expression of Cre recombinase in the developing mouse limb bud driven by a Prxl enhancer. Genesis 33: 77-80.

Long F, Zhang XM, Karp S, Yang Y, McMahon AP. 2001. Genetic manipulation of hedgehog signaling in the endochondral skeleton reveals a direct role in the regulation of chondrocyte proliferation. Development 128: 5099-5108.

Ma Y, Erkner A, Gong R, Yao S, Taipale J, Basler K, Beachy PA. 2002. Hedgehog-mediated patterning of the mammalian embryo requires transporter-like function of dispatched. Cell 111: 63-75.

Mill P, Mo R, Fu H, Grachtchouk M, Kim PC, Dlugosz AA, Hui CC. 2003. Sonic hedgehog-dependent activation of Gli2 is essential for embryonic hair follicle development. Genes Dev 17: 282-294.

Millar SE. 2002. Molecular mechanisms regulating hair follicle development. J Invest Dermatol 118: 216-225.

Niswander L, Jeffrey S, Martin GR, Tickle C. 1994. A positive feedback loop coordinates growth and patterning in the vertebrate limb. Nature 371: 609-612.

Oliver RF, Jahoda CA. 1988. Dermal-epidermal interactions. Clin Dermatol 6: $74-82$.

Oro AE, Higgins K. 2003. Hair cycle regulation of Hedgehog signal reception. Dev Biol 255: 238-248.

Oshimori N, Fuchs E. 2012. Paracrine TGF- $\beta$ signaling counterbalances BMP-mediated repression in hair follicle stem cell activation. Cell Stem Cell 10: 63-75.

Paus R, Muller-Rover S, Van Der Veen C, Maurer M, Eichmuller S, Ling G, Hofmann U, Foitzik K, Mecklenburg L, Handjiski B. 1999. A comprehensive guide for the recognition and classification of distinct stages of hair follicle morphogenesis. I Invest Dermatol 113: 523-532.

Pennisi D, Bowles J, Nagy A, Muscat G, Koopman P. 2000. Mice null for sox18 are viable and display a mild coat defect. Mol Cell Biol 20: 9331-9336.

Rendl M, Lewis L, Fuchs E. 2005. Molecular dissection of mesenchymal-epithelial interactions in the hair follicle. PLOS Biol 3: e331. doi: 10.1371/journal.pbio.0030331.

Rendl M, Polak L, Fuchs E. 2008. BMP signaling in dermal papilla cells is required for their hair follicle-inductive properties. Genes Dev 22: 543-557.

Richardson GD, Fantauzzo KA, Bazzi H, Maatta A, Jahoda CA. 2009. Dynamic expression of Syndecan-1 during hair follicle morphogenesis. Gene Expr Patterns 9: 454-460.

Rohatgi R, Milenkovic L, Scott MP. 2007. Patched1 regulates hedgehog signaling at the primary cilium. Science 317: 372 376

Rubin LL, de Sauvage FJ. 2006. Targeting the Hedgehog pathway in cancer. Nat Rev Drug Discov 5: 1026-1033.

Sharov AA, Mardaryev AN, Sharova TY, Grachtchouk M, Atoyan R, Byers HR, Seykora JT, Overbeek P, Dlugosz A, Botchkarev VA. 2009. Bone morphogenetic protein antagonist noggin promotes skin tumorigenesis via stimulation of the Wnt and Shh signaling pathways. Am J Pathol 175: 1303 1314.

Sneddon JB, Zhen HH, Montgomery K, van de Rijn M, Tward $A D$, West R, Gladstone H, Chang HY, Morganroth GS, Oro $\mathrm{AE}$, et al. 2006. Bone morphogenetic protein antagonist gremlin 1 is widely expressed by cancer-associated stromal cells and can promote tumor cell proliferation. Proc Natl Acad Sci 103: 14842-14847.
Srinivas S, Watanabe T, Lin CS, William CM, Tanabe Y, Jessell TM, Costantini F. 2001. Cre reporter strains produced by targeted insertion of EYFP and ECFP into the ROSA26 locus. BMC Dev Biol 1: 4. doi: 10.1186/1471-213X-1-4.

St-Jacques B, Dassule HR, Karavanova I, Botchkarev VA, Li J, Danielian PS, McMahon JA, Lewis PM, Paus R, McMahon AP. 1998. Sonic hedgehog signaling is essential for hair development. Curr Biol 8: 1058-1068.

Ting-Berreth SA, Chuong CM. 1996. Sonic Hedgehog in feather morphogenesis: Induction of mesenchymal condensation and association with cell death. Dev Dyn 207: 157-170.

Tusher VG, Tibshirani R, Chu G. 2001. Significance analysis of microarrays applied to the ionizing radiation response. Proc Natl Acad Sci 98: 5116-5121.

Ventura A, Meissner A, Dillon CP, McManus M, Sharp PA, Van Parijs L, Jaenisch R, Jacks T. 2004. Cre-lox-regulated conditional RNA interference from transgenes. Proc Natl Acad Sci 101: 10380-10385.

Weinberg WC, Goodman LV, George C, Morgan DL, Ledbetter S, Yuspa SH, Lichti U. 1993. Reconstitution of hair follicle development in vivo: Determination of follicle formation, hair growth, and hair quality by dermal cells. I Invest Dermatol 100: 229-236.

Xie J, Murone M, Luoh SM, Ryan A, Gu Q, Zhang C, Bonifas JM, Lam CW, Hynes M, Goddard A, et al. 1998. Activating Smoothened mutations in sporadic basal-cell carcinoma. Nature 391: 90-92.

Yauch RL, Gould SE, Scales SI, Tang T, Tian H, Ahn CP, Marshall D, Fu L, Januario T, Kallop D, et al. 2008. A paracrine requirement for hedgehog signalling in cancer. Nature 455: 406-410.

Youssef KK, Van Keymeulen A, Lapouge G, Beck B, Michaux C, Achouri Y, Sotiropoulou, PA, Blanpain C. 2010. Identification of the cell lineage at the origin of basal cell caricinoma. Nat Cell Biol 12: 299-305.

Zhang Y, Tomann P, Andl T, Gallant NM, Huelsken J, Jerchow B, Birchmeier W, Paus R, Piccolo S, Mikkola ML, et al. 2009. Reciprocal requirements for EDA/EDAR/NF- $\kappa \mathrm{B}$ and Wnt/ $\beta$-catenin signaling pathways in hair follicle induction. Dev Cell 17: 49-61.

Zuniga A, Haramis AP, McMahon AP, Zeller R. 1999. Signal relay by BMP antagonism controls the SHH/FGF4 feedback loop in vertebrate limb buds. Nature 401: 598-602. 


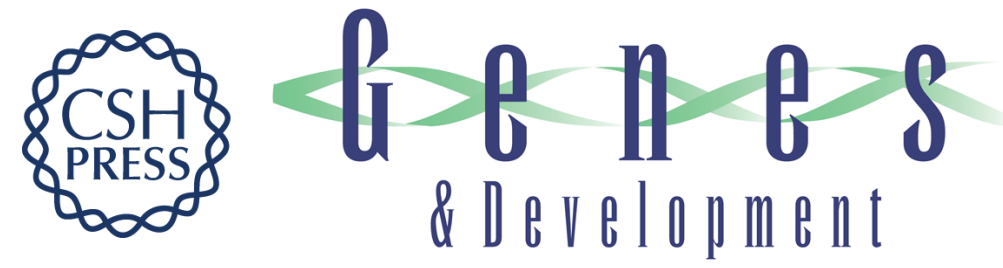

\section{Shh maintains dermal papilla identity and hair morphogenesis via a Noggin-Shh regulatory loop}

Wei-Meng Woo, Hanson H. Zhen and Anthony E. Oro

Genes Dev. 2012, 26:

Access the most recent version at doi:10.1101/gad.187401.112

Supplemental http://genesdev.cshlp.org/content/suppl/2012/05/30/26.11.1235.DC1
Material

References This article cites 65 articles, 22 of which can be accessed free at:

http://genesdev.cshlp.org/content/26/11/1235.full.html\#ref-list-1

License

Email Alerting

Receive free email alerts when new articles cite this article - sign up in the box at the top

Service

right corner of the article or click here.

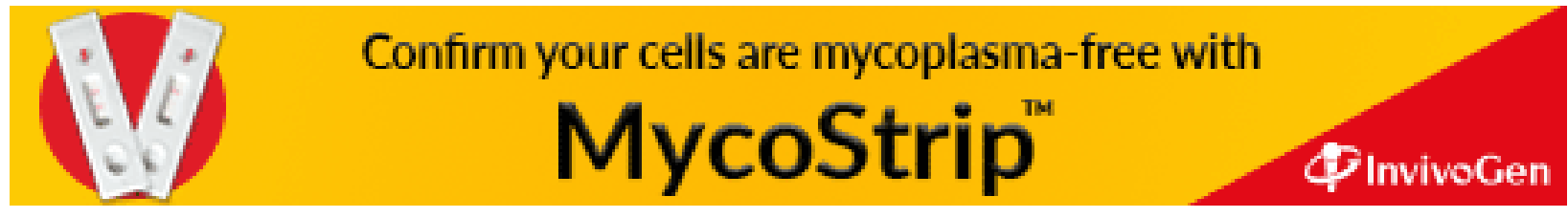

